\title{
Sliding Monitoring System for Ground Wheel Based on ATMEGA16 for No-Tillage Planter-CT246
}

\author{
Lianming Xia, Xiangyou Wang* , Duayang Geng, and Qingfeng Zhang \\ School of Agricultural and Food Engineering, Shandong University of Technology \\ Zibo, Shandong, China \\ xiawj655@163.com, wxy@sdut.edu.cn, dygxt@sdut.edu.cn, \\ zhangqing feng1844@163.com
}

\begin{abstract}
The seed-metering device of the no-tillage planter was driven by the ground wheel. Sliding was unavoidable when the ground was covered by the straw. High sliding brought seeding absence and affected the quality of sowing. In order to monitor the sliding of the ground wheel, a monitoring system composed of hardware and software was designed based on ATMEGA16 Microcomputer. In the system, the practical and the theoretical driving distance of the ground wheel were measured by the photoelectric sensor and rotary encoder respectively, then the sliding can be calculated and displayed on the LED. The system could achieve the data of sliding when the planter worked, and this could insure that the driver may recognize the working conditions at any moment. So it had very important significance which can improve the precision of sow.
\end{abstract}

Keywords: no-tillage planter, sliding, photoelectric sensor, rotary encode, single-chip microcomputer.

\section{Introduction}

Conservation tillage has been defined as tillage and planting system that retains at least $30 \%$ of the cover residues on the soil surface after planting operation is completed. Erosion is reduced by at least $50 \%$ in these soils as compared to bare soils [1][2][3]. Retain crop residues on the soil surface provide a source of plant nutrients, improves organic matter level in the soil, and increase soil water content by reducing evaporation and increasing infiltration rate[4]. In the last three decades, no-till sowing practices that promote soil and water conservation have slowly become an accepted alternative to conventional tillage systems. The precision and no-till seeder has been a key factor in the successful shift to no-till sowing [5]. In the precision and no-till seeder, the seed-metering device which is driven by the ground wheel places seeds at the required spacing. The sliding which can bring seed absence is unavoidable when the field is covered with crop residue and this can affect the quality of sowing.

Moreover, in response to the recent trend toward improving the quality of sowing, many researchers have focused their research on the development of precision

\footnotetext{
* Corresponding author.
} 
seed-metering device and little work has been done to evaluate the sliding for the no-till precision planter. Although it was realized that sliding of ground wheel could affect the quality of sowing, what could do was only to let the tractor drive for a certain distance and then calculate the sliding by counting the number of turns. Then the quantity of sowing can be adjusted based on it. This could only improve the average sliding to a certain extent. However, the quality of sowing could not be improved by only adjusting the quantity of sowing with the varying sliding. In this research, a sliding monitoring system based on the technologies of single-chip microcomputer and sensor was designed to help the driver realize the sliding at real-time.

\section{Analysis of the Sliding Monitoring Theory}

The sliding of the ground wheel is caused by the different driving distances between the tractor and the ground wheel. So, the sliding can be calculated by the formula below

$$
\eta=\frac{s_{1}-s_{2}}{s_{1}} \times 100 \%
$$

Where $s_{1}$ is the practical distance the tractor drives, $s_{2}$ the theoretical distance the ground wheel drives [6].

A five-wheel gauge was usually used to measure the practical distance of the ground wheel drove. However, the result was often affected by the factors such as the bounce of the fifth wheel brought by the ground flatness, the difference between the arc and lineal length of the ground surface, the sliding which was caused by the no-pure rolling between the fifth wheel and the ground. In the no-tillage sowing, the ground is covered by a lot of crop residue. So, the error would be very obvious when it was measured by the five-wheel gauge [7]. In this paper, the practical driving distance is measured by the photoelectric sensor and this is showed in Fig1.

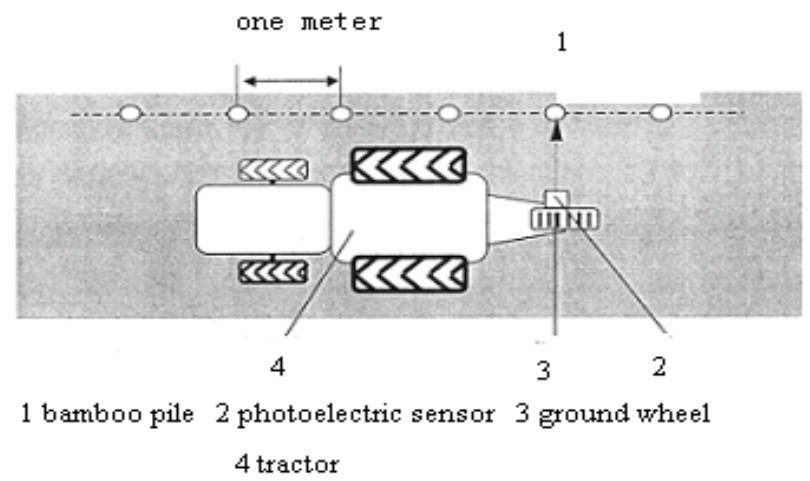

Fig. 1. The theory for measurement of the practical driving distance 


\section{The Structure of the Monitoring System}

In this paper, the single-chip microcomputer used is ATMEGA16. Its pins are showed in Fig2.

\begin{tabular}{|c|c|c|c|}
\hline \multirow[b]{2}{*}{1} & 1 & & \multirow[b]{2}{*}{40} \\
\hline & \multirow{3}{*}{$\begin{array}{l}\mathrm{PB} 0(\mathrm{XCT} / \mathrm{T} 0) \\
\mathrm{PB} 1(\mathrm{~T} 1)\end{array}$} & \multirow{2}{*}{ (ADC0)PA0 } & \\
\hline 2 & & & 39 \\
\hline 3 & & (ADC1)PA1 & 38 \\
\hline 4 & $\begin{array}{l}\mathrm{PB} \text { (IN12/AINO) } \\
\mathrm{PB} 3(\mathrm{ACO} / \mathrm{AN1}\end{array}$ & $(A D C 2) P A 2$ & 37 \\
\hline 5 & $\mathrm{~PB} 3(\mathrm{OCO} / \mathrm{AIN} 1)$ & $(\mathrm{ADC} 3) \mathrm{PA} 3$ & 36 \\
\hline 6 & $\begin{array}{l}\text { PB4(SS) } \\
\text { PB5OMOSD }\end{array}$ & (ADC4)PA4 & 35 \\
\hline 7 & PB5(MOSI) & (ADC5)PA5 & 34 \\
\hline 8 & $\begin{array}{l}\text { PB7(SCK) } \\
\text { PBO(NISU) }\end{array}$ & (ADC7)PA7 & 33 \\
\hline 9 & $\frac{\mathrm{PB} 7(\mathrm{SCK})}{\mathrm{PFSET}}$ & (ADC7)PA7 & 32 \\
\hline 10 & $\begin{array}{l}\text { KESE T } \\
\text { VCC }\end{array}$ & $\begin{array}{l}\text { AREF } \\
\text { GND }\end{array}$ & 31 \\
\hline 11 & VCC & UND & 30 \\
\hline 12 & GTA 2 & $\begin{array}{r}\text { Avec } \\
\text { (TOSC }) \mathrm{PC} 7\end{array}$ & 29 \\
\hline 13 & $\begin{array}{l}\text { XIALZ } \\
\text { XTAL1 }\end{array}$ & (TOSC1)PC6 & 28 \\
\hline 14 & $\begin{array}{l}\text { XIAL1 } \\
\text { PDO(RXD) }\end{array}$ & $\begin{array}{l}\text { (10SC1)PC6 } \\
\text { (TDDPC5 }\end{array}$ & 27 \\
\hline 15 & $\begin{array}{l}\text { PDU(KXD) } \\
\text { PDI(TXD) }\end{array}$ & (IDI)PCS & 26 \\
\hline 16 & $\begin{array}{l}\text { PDI(IXD) } \\
\text { PD?(INTO) }\end{array}$ & (TMS)PC3 & 25 \\
\hline 17 & PD3(INT1) & (TCK)PC2 & 24 \\
\hline 18 & PD4(OC1B) & (SDA)PCI & 23 \\
\hline 19 & $\mathrm{PD} 5(\mathrm{OCl})$ & (SCL)PCO & 22 \\
\hline 20 & $\begin{array}{l}\text { PD6(ICP1) } \\
\text { (ICP) }\end{array}$ & $(\mathrm{OC} 2) \mathrm{PD} 7$ & 21 \\
\hline & 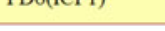 & & \\
\hline
\end{tabular}

Fig. 2. The pins of ATMEGA16

\subsection{The Circuits of the Sensors}

In this paper, the model of the photoelectric sensor used is E3F-DS60C4 which can detect the signals in 70-centimeter range. The rotary encode E6B2-CWZ6C is produced by

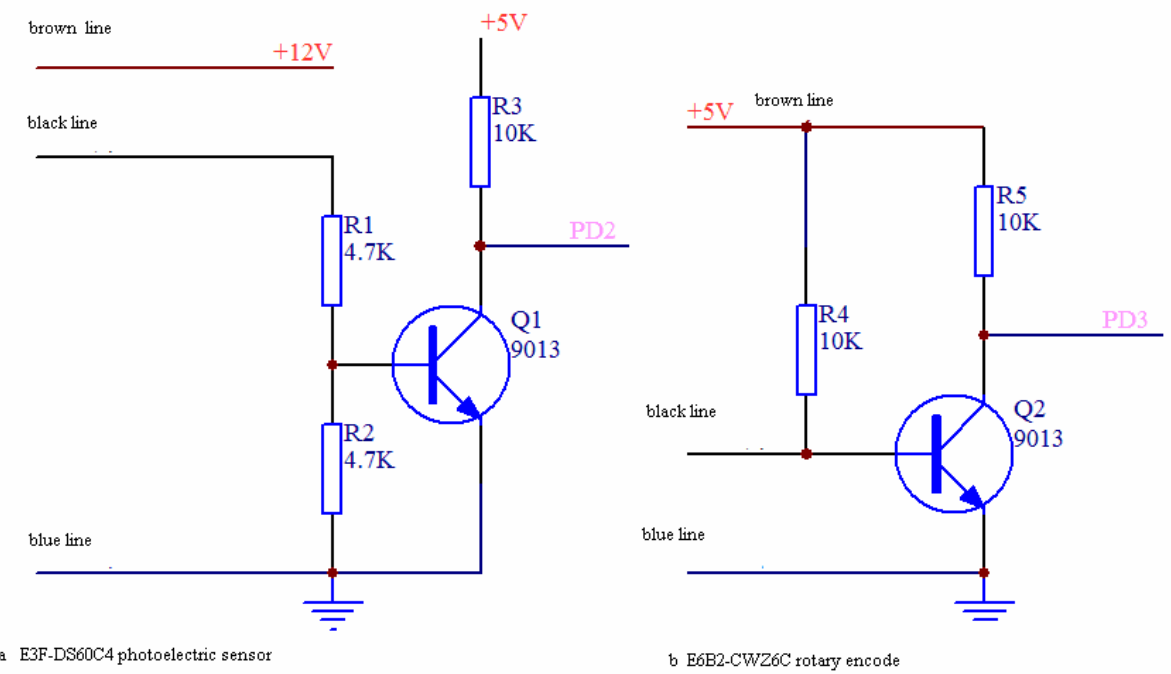

Fig. 3. The circuits of the sensors 
the company of OMRON and it can send out 360 pulse sis when the ground wheel revolves for a round [8] [9]. The circuits of the sensors are showed in Fig3.

From Fig2 and Fig3, it can be seen that the photoelectric sensor and the rotary encode are connected to PD2 and PD3 which are the external interruption pins of ATMEGA16. The output level sent out from PD2 is high when the photoelectric sensor is near the bamboo pile and low when it is away from it. The PD3 pin sends out high LEVEL when the rotary encode revolves and low or high level when it does not revolve [10]. All interruptions are triggered at the falling edge. Although the photoelectric sensor and the rotary encode can send out changing level, it can not absorb and send out too high current, or it can not make the current of the interruption pin be low. So a PNP9013 is used as switch in Fig3.

\subsection{Design of the LCD Circuit}

In the monitoring system, LCD12864 with FLASH is used to show the sliding of the ground wheel. Its wiring diagram is showed in Fig4.

As showed in Fig4, port LCDDATA is used as the I/O port of LCD, LED and the four-digit digital diode. It is also the extension of PA. Its ports are composed of ten groups of two-pin jumpers which are linked to the pin MAMBD. The pins of the LCDDATA from left to right are showed in Table1.

LCDControl is the extended port of PB which is the control port of LCD12864 or LCD1602. The ports of LCDControl are composed of five group two-pin jumpers which are linked to pin PB0 to PB4 of M2MD1.0. The pins of port LCDControl are showed in Table2.

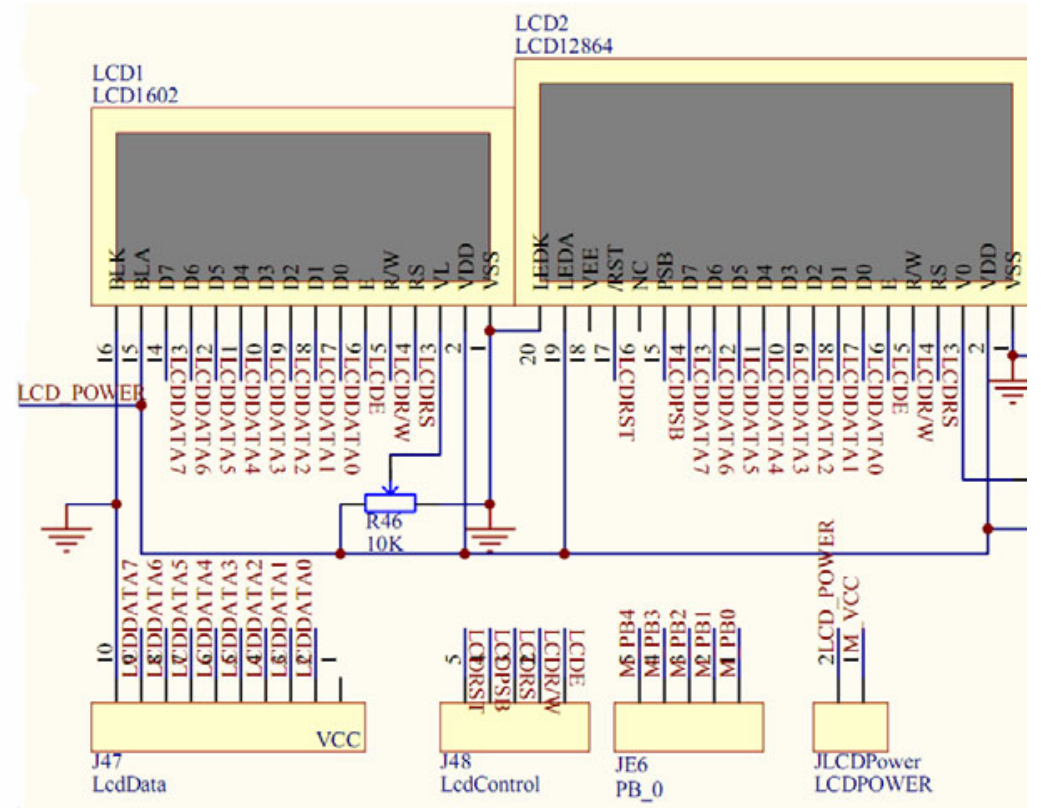

Fig. 4. Wiring diagram of LCD12864 
Table 1. The pins of LCDDATA

\begin{tabular}{|l|l|l|l|l|l|l|l|l|l|}
\hline & D7 & D6 & D5 & D4 & D3 & D2 & D1 & D0 & \\
\hline GND & PA7 & PA6 & PA5 & PA4 & PA3 & PA2 & PA1 & PA0 & VCC \\
\hline
\end{tabular}

Table 2. The pins of LCDControl

\begin{tabular}{|l|l|l|l|l|}
\hline E & RW & RS & PSB & RST \\
\hline PBD & PE1 & PB2 & PB3 & PB4 \\
\hline
\end{tabular}

The wiring diagram of the monitoring system is showed in Fig5.

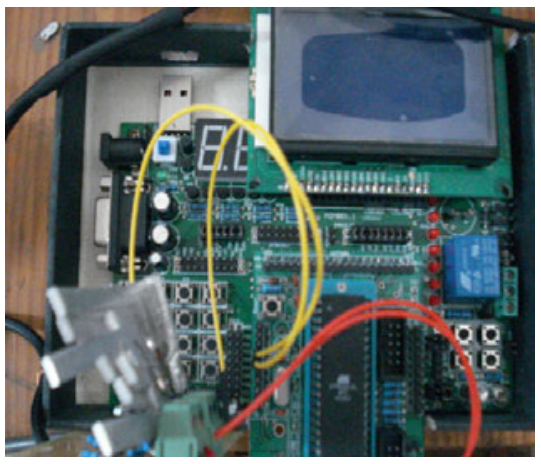

Fig. 5. Wiring diagram of the monitoring system

\section{Design of Software System}

In the main program, four global variables and one global array are set. In the array, only three elements are used. The interrupt 0 and 1 are used to count the numbers of

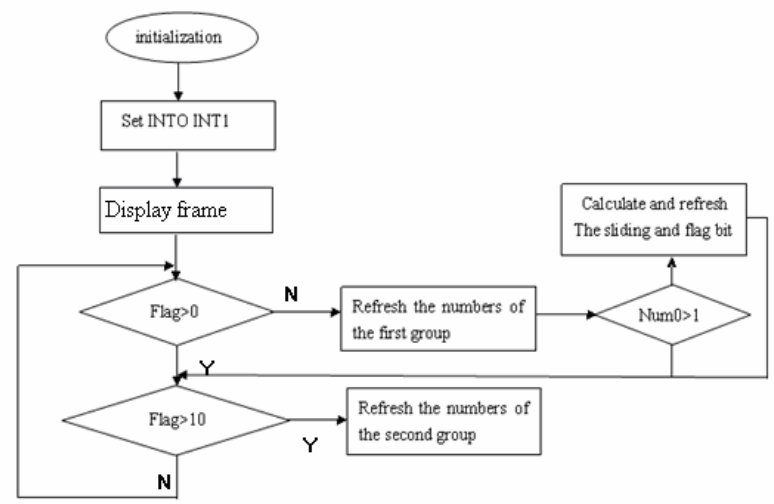

Fig. 6. Flow chart of the main program 
Pulse signals from the photoelectric sensor and the rotary encode. In the interruption system, flag bit num0 and num1, flag0 and flag1 are needed to be updated. The screen will blink when interruption0 counts one pulse signals and interruption 1 counts ten pulse signals. The value of the sliding will refresh when the interruptions count twice and at the same time all flag bits are cleared. In this system, rate 0 and rate 1 are used to indicate the distances when one impulse signal is interrupted. The flow chart of the main program is showed in Fig6 [11].

\section{Experiments and Discussion}

In the experiments, the factors which can affect the sliding are the soil conditions, the parameters of the ground wheel and the vertical load on the wheel [12]. In order to test the performance of the monitoring system, some ground wheels with different parameters and vertical loads were chosen to work in different soils. The parameters of the ground wheel and the vertical load were showed in Table3.

Table 3. The parameters of the ground wheel

\begin{tabular}{|c|c|c|c|}
\hline level & 1 & 2 & 3 \\
\hline $\begin{array}{l}\text { the rettical load } \\
\text { G(kg) }\end{array}$ & 150 & 50 & 100 \\
\hline $\begin{array}{l}\text { the width of the wheel } \\
\mathrm{B} \text { (tuttil) }\end{array}$ & 130 & 70 & 100 \\
\hline $\begin{array}{l}\text { the height of clutching } \\
\text { boatd H(tumin) }\end{array}$ & 40 & 0 & 20 \\
\hline
\end{tabular}

Table 4. The results of the experiments with different ground wheels

\begin{tabular}{|c|c|c|c|c|}
\hline \multirow{2}{*}{ tumber } & \multicolumn{3}{|c|}{ experiments with ground whe } & \multirow{2}{*}{ sliding $(\%)$} \\
\hline & Fertical load( $\mathrm{kg})$ & width(tum) & height of chutchitig board(tum) & \\
\hline 1 & 150 & 130 & 40 & $13.72 \%$ \\
\hline 2 & 50 & 130 & 40 & $15.56 \%$ \\
\hline 3 & 50 & 70 & 40 & $17.12 \%$ \\
\hline 4 & 100 & 1010 & 20 & $1804 \%$ \\
\hline 5 & 150 & 130 & 0 & $1798 \%$ \\
\hline
\end{tabular}

According to the parameters of Table3, five ground wheels with different parameters were chosen to test the performance of the system, the parameters and results were showed in Table4. 
From the results above, it could be seen that the monitoring system correctly tested the sliding of the ground wheels with different parameters.

\section{Conclusions}

In this paper, an automatic instrument based on the technologies of sensor and singlechip microcomputer was used for precision planter. It could measure the sliding of the ground wheel when the tractor drove on the soil which was covered by the straws at real-time. The driver could recognize the sliding of the ground wheel and this would help him control the quality of sowing timely.

\section{References}

1. Karayel, D.: Performance of a Modified Precision Vacuum Seeder for No-till Sowing of Maize and Soybean. J. Soil \& Tillage Research 104, 121-125 (2009)

2. Dawelbeit, M., Babiker, E.A.: Effect of Tillage and Method of Sowing on Wheat Yield in Irrigated of Rahad, Sudan. J. Soil \& Tillage Research 42, 127-132 (1997)

3. Barut, Z.B.: Determination of the Optimum Working Parameters of a precision Vacuum Seeder. PhD Thesis University of Cukuriva, Adana, Turkey (1996)

4. Wang, Q., Chen, H., Li, H., Li, W., Wang, X., McHughb, A.D., He, J., Gao, H.: Controlled traffic farming with no tillage for improved fallow water storage and crop yield on the Chinese Loess Plateau. J. Soil \& Tillage Research 104, 192-197 (2009)

5. Baker, C.J., Saxton, K.E., Ritchie, W.R.: No-tillage Seeding and Practice, 2nd edn. CAB international, Oxford (2002)

6. Gao, Y.: Ground wheel Slide of no Tillage Seeding-machine. China Agricultural University (December 2001)

7. Zhang, B., Yu, Q.: The simulation study of sliding For wheeled tractor based on PD control. Journal of Beijing Agricultural University (February 1995)

8. http://www. fa.omron.com.cn

9. Xu, L., Zhao, Y.: Design of Incremental Photoelectrical Encoder Interface Based on Single-chip. Machinery \& Electronics 12, 10-11 (2006)

10. Cui, Y.: A Design Instance of Measurement System for Rotary Speed Based on Photoelectric Encoder. Management and Development 10, 74-75 (2007)

11. Taner, A.H.: Virtual instrumentation: a solution to the problem of design complexity in intelligent measurement/control 7, 165-171 (1996)

12. Walsh, P., Jenson, T.: Towards a Standard for Controlled Traffic Machinery. In: Proceeding of the Second National Controlled Traffic Conference of Australia, pp. 27-28 (1999) 